\title{
Keeping track of hidden dangers - The short history of the Sabiá virus
}

\author{
Joel Henrique Ellwanger ${ }^{[1]}$ and José Artur Bogo Chies ${ }^{[1]}$
}

\author{
[1]. Laboratório de Imunogenética, Programa de Pós-Graduação em Genética e Biologia Molecular, Departamento de Genética, \\ Universidade Federal do Rio Grande do Sul, Porto Alegre, RS, Brasil.
}

\begin{abstract}
Emerging infectious diseases are a global threat. In countries like Brazil, where biodiversity is high and public health conditions in terms of infrastructure and medical care are often precarious, emerging diseases are particularly worrisome. The lack of monitoring strategies to identify pathogens with the potential to cause outbreaks or epidemics is another problem in Brazil and other developing countries. In this article, we present the history of the Sabiá virus (SABV), a pathogen that was described in the 1990s in Brazil. Several aspects of the biology and ecology of the SABV remain unknown. The SABV has the potential to cause hemorrhagic fever in humans. To date, four cases of human infections have been reported worldwide; two were naturally acquired (both in Brazil), whereas the other two were linked to occupational exposure in the laboratory environment (one in Brazil and one in the USA). In this review, we summarize the basic biological and ecological characteristics of the SABV. This is the first work to gather all available data on the historical aspects involving the cases of SABV infection along with an update on its characteristic features.
\end{abstract}

Keywords: Arenaviridae. Emerging viral disease. Sabiá virus. Viral ecology.

\section{INTRODUCTION}

Brazil has abundant biodiversity. Brazilian ecosystems likely hide many pathogens that can cause infectious diseases in humans. This is relevant for public health as these pathogens could cause diseases with unknown characteristics. When pathogens are newly introduced into the human population, this poses significant challenges and dangers as the population is not immunized against these organisms. Potential vaccines have yet to be developed, which typically requires a time-consuming process. Moreover, the lack of knowledge on the biology and ecology of these infectious agents represents an obstacle to prevention and containment strategies of potential epidemics.

In this review, we are highlighting the Sabiá virus (SABV), which, although described in the 1990s, has not been well studied. Briefly, it is known that this arenavirus circulates in Brazil and can cause hemorrhagic fever in humans. However, little is known about the virus' biology and ecology.

Considering the paucity of information on this pathogen, the aims of this article were to gather available information on the $\mathrm{SABV}$ and to describe the four reported cases of SABV infection within a historical perspective. Some aspects of SABV ecology and biology will also briefly be discussed.

Corresponding author: Dr. José Artur Bogo Chies.

e-mail: jabchies@terra.com.br; joel.ellwanger@gmail.com

Received 18 October 2016

Accepted 7 February 2017

\section{METHODOLOGY}

This study is a narrative review. We consulted the following regional and international databases: Biblioteca Virtual em Saúde (BVS; http://bvsalud.org/), MEDLINE (via PubMed; https://www.ncbi.nlm.nih.gov/pubmed), and The Scientific Electronic Library Online (SciELO; http://www.scielo.org/). Keywords used to search for articles on the SABV included sabia virus and $S A B V$. Using the search term sabia virus, we found 622, 788, and 9 articles in the BVS, MEDLINE, and SciELO, respectively. The search term $S A B V$ uncovered 3 articles in the BVS, 10 in MEDLINE, and none in SciELO. After we analyzed the articles through their abstracts or full texts regarding its relevance, 24 of them were selected to be included in our review. When necessary, reference lists of previously published studies were consulted to select and locate articles. Eight works discussing topics such as arenavirus, emerging virus, and viral ecology were also included in this review aiming to complement our discussion on these topics.

\section{Basic aspects of the Sabiá virus}

Classification and geographic distribution of the Sabia virus and other arenaviruses - The SABV belongs to the family Arenaviridae, and within these arenaviruses to the Tacaribe or New World complex. Arenaviruses are enveloped negativestranded RNA viruses ${ }^{1-3}$. In addition to the SABV, the New World complex includes the following 17 viruses: Allpahuayo (Peru), Amapari (Brazil), Bear Canyon (California, USA) 
Chapare (Bolivia), Cupixi (Brazil), Flexal (Brazil), Guanarito (Venezuela), Junin (Argentina), Latino (Bolivia), Machupo (Bolivia), Oliveros (Argentina), Parana (Paraguay), Pichinde (Colombia), Pirital (Venezuela), Tacaribe (Trinidad), Tamiami (Florida, USA), and Whitewater Arroyo (Southwestern USA.). It seems that Brazil is the natural place of occurrence of the SABV (reviewed in Radoshitzky et al. ${ }^{4}$ ).

In 1996, phylogenetic analyses (of a portion of the nucleocapsid gene) resulted in the classification of the $\mathrm{SABV}$ as a unique member of the clade B of the New World arenaviruses ${ }^{2}$. Previous studies that had evaluated the complete glycoprotein precursor, complete nucleoprotein, and polymerase genes as well as the phylogenetic relationships among New World arenaviruses had resulted in the same classification ${ }^{5-7}$. According to Radoshitzky et al. ${ }^{4}$, eight arenaviruses belong to the clade B: Amapari, Chapare, Cupixi, Guanarito, Junin, Machupo, Sabiá, and Tacaribe. Non-genetic factors such as geographical regions of occurrence, hosts, or the potential to cause epidemics are not good indicators to correlate different groups of arenaviruses 5 .

Viral host and route of infection - Commonly, naturally acquired human infections by arenaviruses are caused by viruses with rodent hosts ${ }^{8}$. Rodents are likely also reservoirs for the SABV. Recently, Bisordi et al. ${ }^{9}$ identified arenavirus sequences in 5 of 55 vesper mice (Calomys tener) that were caught in the area where the second naturally acquired infection with the SABV was identified (Espírito Santo do Pinhal, São Paulo State, Brazil); however, all sequences were different from those that had been described for the SABV. Notably, their study resulted in the identification of a new arenavirus, the Pinhal virus9.

Generally, arenaviruses are transmitted through contact with contaminated rodent urine ${ }^{10}$. Thus, inhalation of dust mixed with rodent urine is the probable route of infection by the SABV in nature. Future studies should aim at identifying the presence of the virus in samples of excreta and biological fluids of rodents.

Clinical implications and pathogenesis of Sabiá virus infections - Arenaviruses found in the Americas that are pathogenic in humans include Chapare, Flexal, Junin, Pichinde, Guanarito, Machupo, Tacaribe, and the SABV. The potential of the Allpahuayo, Amapari, Cupixi, Parana, Pirital, Latino, and Oliveros viruses to cause diseases in humans is unknown (reviewed in Koma et al. ${ }^{11}$ ).

In general, symptoms caused by the SABV are abdominal and epigastric pain, bleeding gums, conjunctival petechiae, conjunctivitis, cough, diarrhea, difficulty walking, fever, headache, hematemesis, hemorrhage, leukopenia, malaise, myalgia, nausea, somnolence, sore throat, tonic-clonic seizures, tremors, vomiting, weakness, and shock ${ }^{1,12}$.

An in vitro study performed by Radoshitzky et al..$^{13}$ indicated that the SABV infects host cells through the transferrin receptor 1 (TfR1) as virus replication was halted by administering an anti-TfR1 antibody. Based on these data, it is plausible that the hemorrhagic fever caused by the SABV is related to the virus' capacity to bind to human TfR1. Other study in vitro also shown that the SABV Z protein interacts with the retinoic acid-inducible gene I product (RIG-I) and downregulates the cellular beta interferon response ${ }^{14}$.
The $\mathrm{SABV}$ is considered a dangerous pathogen as it can induce a severe hemorrhagic fever that can rapidly progress to the death of the infected individual ${ }^{15}$.There is no specific treatment for the disease or immunoprophylaxis for the virus. One might ask, Why, almost 30 years after the first report of human SABV infection, is knowledge on SABV biology and pathogenesis still so limited? Similarly, considering that the last case of naturally acquired human infection was reported in 1999, How can the absence of new cases within the last 17 years be explained? Some potential answers might be: I) New human infections are occurring but are not being reported due to the similarity of the clinical symptoms with those of other viral infections; II) The habitat of the reservoir species is not conducive to human interaction, which could hinder the infection of humans by the virus; and III) The transmission capacity of the virus from natural reservoir species to humans is low. However, it is important to identify the reservoir species of the SABV. Once the reservoir species is known, experimental studies aimed at elucidating the pathophysiological aspects of SABV infection should be conducted.

Viral detection and potential anti-viral strategies - Detection of the SABV in humans remains a clinical and methodological challenge. Machado et al. ${ }^{16}$ report the need for developing techniques to detect the SABV without having to manipulate infectious viral samples. Currently, there is a well-described reverse transcription polymerase chain reaction (RT-PCR) assay for the rapid detection of the $\mathrm{SABV}^{17}$.

Figueiredo ${ }^{18}$ suggested that the vaccine against the Junin virus (that is already being used in Argentina) could also induce immunity to the SABV. However, his hypothesis needs to be confirmed. Recently, Golden et al. ${ }^{19}$ described a DNA vaccine that could be used as a pan-arenavirus immunotherapeutic.

The compounds ST-193 and ST-294 have been shown to possess anti-viral activity for arenaviruses ${ }^{20-22}$. The target of ST-193 is likely a segment of about 30 amino acids within the envelope of the glycoprotein 2 subunit $^{21}$. ST-294 targets the interaction of the transmembrane fusion subunit with the stable signal peptide, and then interferes with envelope glycoprotein-mediated membrane fusion ${ }^{22}$. However, these results were primarily derived from experiments focused on the Lassa and Junin viruses ${ }^{21,22}$. Although there is no sufficient evidence to confirm that ST-193 and ST-294 can be used for the SABV, it is possible that these compounds also have anti-SABV activity. The similarities in envelope composition between the SABV, Lassa, and Junin viruses need to be assessed to be able to extrapolate the results ${ }^{21,22}$ mentioned above.

Clinical and experimental evidence has shown that the antiviral drug ribavirin can be used to treat SABV infection ${ }^{23,24}$. As Radoshitzky et al. ${ }^{25}$ have suggested, antiviral drugs focused on viral transcription and replication can work through different routes. Because of that, structural studies on arenaviral RNAdependent RNA polymerase and nucleoprotein could facilitate the development of antiviral drugs that are effective for the treatment of New World arenavirus infections.

\section{Four documented cases of Sabiá virus infection}

Only four cases of SABV infection have been reported to date (Table 1). Herein, infections that occurred outside the 
TABLE 1

Summary of the four cases of Sabiá virus infection.

\begin{tabular}{|c|c|c|c|c|c|}
\hline Case & Year & Location & Situation & Outcome & Reference \\
\hline First & 1990 & São Paulo State, Brazil & Naturally acquired infection & Fatal & Coimbra et al. ${ }^{1}$ \\
\hline Second & 1992 & Pará State, Brazil & $\begin{array}{l}\text { Occupational exposure } \\
\text { (laboratory environment) }\end{array}$ & Non-fatal & Vasconcelos et al. ${ }^{27}$ \\
\hline Third & 1994 & Yale University, Connecticut (USA) & $\begin{array}{l}\text { Occupational exposure } \\
\text { (laboratory environment) }\end{array}$ & Non-fatal & $\mathrm{CDC}^{28}$ \\
\hline Fourth & 1999 & São Paulo State, Brazil & Naturally acquired infection & Fatal & Coimbra et al. ${ }^{12}$ \\
\hline
\end{tabular}

USA: United States of America; CDC: Centers for Disease Control and Prevention.

laboratory environment will be termed naturally acquired infections. Detailed information on the relevant aspects of each case are presented below.

First (index) case - The SABV was first isolated in 1990 from a fatal case of hemorrhagic fever in São Paulo State (Southeastern Brazil). This index case was a 25-year-old female agricultural engineer who experienced fever, myalgia, headache, nausea, vomiting, and weakness for 12 days before seeking medical attention. She eventually developed conjunctival petechiae, hematemesis, vaginal bleeding, increased sleepiness, tremors, difficulty walking, and generalized tonic-clonic seizures; she died of the infection on the fourth day of hospital admission. The necropsy indicated necrosis of and hemorrhage in various organs ${ }^{1}$.

After a series of tests performed on a blood sample of the patient at the Instituto Adolfo Lutz (Brazil), Instituto Evandro Chagas (Brazil), Yale Arbovirus Research Unit (USA), and U.S. Army Medical Research Institute of Infectious Diseases (USA), the causative agent of the disease was identified as a new virus of the family Arenaviridae. The pathogen was named after the district where the patient lived, Sabiá. Until then, only four arenaviruses causing hemorrhagic fevers were known: Lassa, Junin, Machupo, and Guaranito ${ }^{1}$. SABV causes the disease now known as Brazilian hemorrhagic fever or São Paulo hemorrhagic fever ${ }^{26}$

Second case - While working on the characterization of the SABV in a reference laboratory in Pará State (Brazil), a 39-year-old male laboratory technician was infected with the virus (probably through aerosol) in 1992. He developed a prolonged influenza-like illness. However, this case was not fatal, possibly because the patient had sought medical attention and received treatment (basically fluid control) soon after the first symptoms appeared ${ }^{1,27}$.

Third case - Similar to the second case, the third case of infection with clinical disease caused by the SABV happened in 1994. It was an accidental laboratory exposure, likely linked to aerosol transmission. During routine work in a biosafety level 3 laboratory, a 46-year-old male research scientist at Yale University (USA) was infected with the virus after an accident involving a bucket centrifuge. After centrifugation of approximately $240 \mathrm{~mL}$ supernatant from a tissue culture infected with SABV, the researcher realized that the tube used for the centrifugation was broken, and that a large portion of container contents (approximately $100 \mathrm{~mL}$ ) had leaked into the rotor of the centrifuge. The infection possibly happened by a leaking rotor or during the cleaning/opening procedure of the centrifuge, although the researcher was not directly exposed to the leaked content and used personal protective equipment ${ }^{8,23,28,29}$. Human error was recognized as the principal factor causing this incident ${ }^{30}$.

This patient fell ill but survived after being hospitalized and receiving the antiviral drug ribavirin. Based on this case, it could be suggested that ribavirin could be used to treat future cases of SABV infection ${ }^{23}$. Supporting this, evidence exists that ribavirin can be used to treat Argentine hemorrhagic fever, which is caused by the Junin virus ${ }^{24}$.

Considering that two SABV infections occurred during work routines in reference laboratories with biosafety equipment, it is likely that the SABV is transmitted through aerosol. Thus, additional biosafety precautions should be undertaken when handling the virus ${ }^{23}$. Currently, it is recommended to handle the SABV in biosafety level 4 laboratories ${ }^{31}$.

Fourth case - The fourth case of SABV infection was reported in 1999 and was naturally acquired. A 32-year-old male coffee-grain machine operator, resident of a rural area (Espírito Santo do Pinhal) of the São Paulo State, presented with a febrile illness. After hospitalization for seven days, the patient died. It was found that the SABV was responsible for the pathological condition of the patient ${ }^{12}$. Similar to the second case, little information is available in the literature on this fourth case of SABV infection.

\section{Eco-epidemiological aspects of naturally acquired Sabiá virus infections}

Due to the scarcity of studies on the identification of the SABV host species and its circulation among different animals, little is known about the eco-epidemiological aspects of naturally acquired SABV infections. Similarly, to the best of our knowledge, no serological study has been conducted in populations living in locations where the two cases of natural acquired SABV infections were identified. Serological and epidemiological studies are particularly necessary to assess 
the epidemiology, routes of transmission, and prevalence of infection of the virus among humans. Importantly, subclinical SABV infections might occur without being identified.

The difference in locations (urban area vs. rural region of São Paulo State) of the two naturally acquired infections is worthy of further investigation. Due to the typical characteristics (activities in open areas, proximity to forest environments, among others) of the rural environment that propitiate the closest coexistence of humans and wild rodents, infections by arenaviruses are quite plausible. Farming activities undertaken by the infected man are thought to have facilitated his exposure to rodent excreta $^{12}$.

The SABV circulation in non-human animals of urban areas was little investigated. Recently, Bisordi et al..$^{9}$ performed a serological investigation among rodents that were captured in the city (Espirito Santo do Pinhal) where this case was reported to identify the host rodent species of the SABV. A total of 412 rodents of 7 different species (Necromys lasiurus, $\mathrm{n}=164$; Akodon spp., $\mathrm{n}=116$; Calomys tener, $\mathrm{n}=68$; Mus musculus, $\mathrm{n}=55$; Oligoryzomys nigripes, $\mathrm{n}=7$; Bibimys labiosus, $\mathrm{n}=1$; and Rattus rattus, $\mathrm{n}=1$ ) were evaluated. However, none of the rodents showed evidence of SABV infection.

The factors facilitating SABV infection in an urban environment are even less understood. It is only known that the index patient worked in an office, had not traveled outside São Paulo State two months before becoming sick, and spent time in two different cities of São Paulo State with family and friends ten days prior to the symptoms. No family member or friend got sick ${ }^{1}$. A study investigating the activities performed by the patient a few days before the symptoms might help explain the conditions (mainly route of infection and contact with potential SABV hosts) that facilitated the infection. However, such a retrospective investigation is not feasible. Thus, studies investigating the potential host species of the SABV and serological studies should be conducted in the urban area where the first case of naturally acquired SABV infection was identified.

\section{Perspectives on the ecology and surveillance of the arenaviruses}

Infections linked to occupational exposure can be avoided by applying more stringent biosafety measures when handling the SABV. However, it is difficult to predict if naturally acquired infections will occur, since the ecology of the virus is poorly understood.

Taking into consideration the wide Brazilian biodiversity and the potential viruses existing within it, studies on viral ecology in the Brazilian ecosystem should be performed. This is important because only indentifying the pathogens, their hosts, and their potential to infect different species, will it be possible to prevent and combat new diseases and future potential epidemics that might affect humans ${ }^{32}$. Studies on zoonotic diseases may support strategies for controlling the circulation of pathogens between human and wild/domestic animals. However, studying the ecology of viral zoonoses and broadspectrum surveillance are rather expensive because it generally involves a great number of professionals from various areas, survey of a large number of biological samples from human and non-human animals, and different methodologies of viral detection. Considering that developing countries are often most affected by tropical infectious diseases, conducting these studies might not be financially feasible. Thus, to develop public health strategies to detect adequately human and veterinary diseases and their zoonotic sources is essential. In addition, establishing simple and well-structured medical surveillance and reporting systems are important for the epidemiological control of viral diseases.

\section{CONCLUSION}

Figure 1 depicts the main events related to the history of the SABV. To date, four cases of SABV infection (two naturally acquired and two linked to occupational exposure in laboratories) have been reported in the literature. Little is known about the ecology of the SABV. In addition, the virus' reservoir species are unknown, although they are likely rodents. To date, the available data indicate that SABV is found naturally in Brazil; however, its occurrence in other countries cannot be ruled out. Current guidelines recommend handling the virus only in a biosafety level 4 environment. The antiviral drug ribavirin might be useful for the treatment of SABV infection in humans. The potential of the virus to cause an outbreak or epidemic is not known, but should not be overlooked by the scientific and medical communities.

Since many questions on the threat posed by the SABV, other viral pathogens, and recent outbreaks involving emerging viruses remain, studies on viral ecology (in particular in tropical countries) should be encouraged. Moreover, strategies to control potential outbreaks must be planned. Specific to the SABV, we strongly suggest that it is crucial to: I) identify the viral reservoir species; II) investigate the geographic regions of occurrence of the host/pathogen; III) identify routes of infection; IV) develop or identify antiviral treatments; V) establish rapid and accurate methods for diagnosis; VI) establish standards and recommendations for scientific research with this pathogen to ensure safety of researchers. Due to the scarce number of studies focused on SABV, to investigate this virus presents an opportunity for the discovery of important aspects of its biology, pathogenesis, and ecology.

\section{Conflicts of interest}

The authors declare that they have no conflict of interest. 


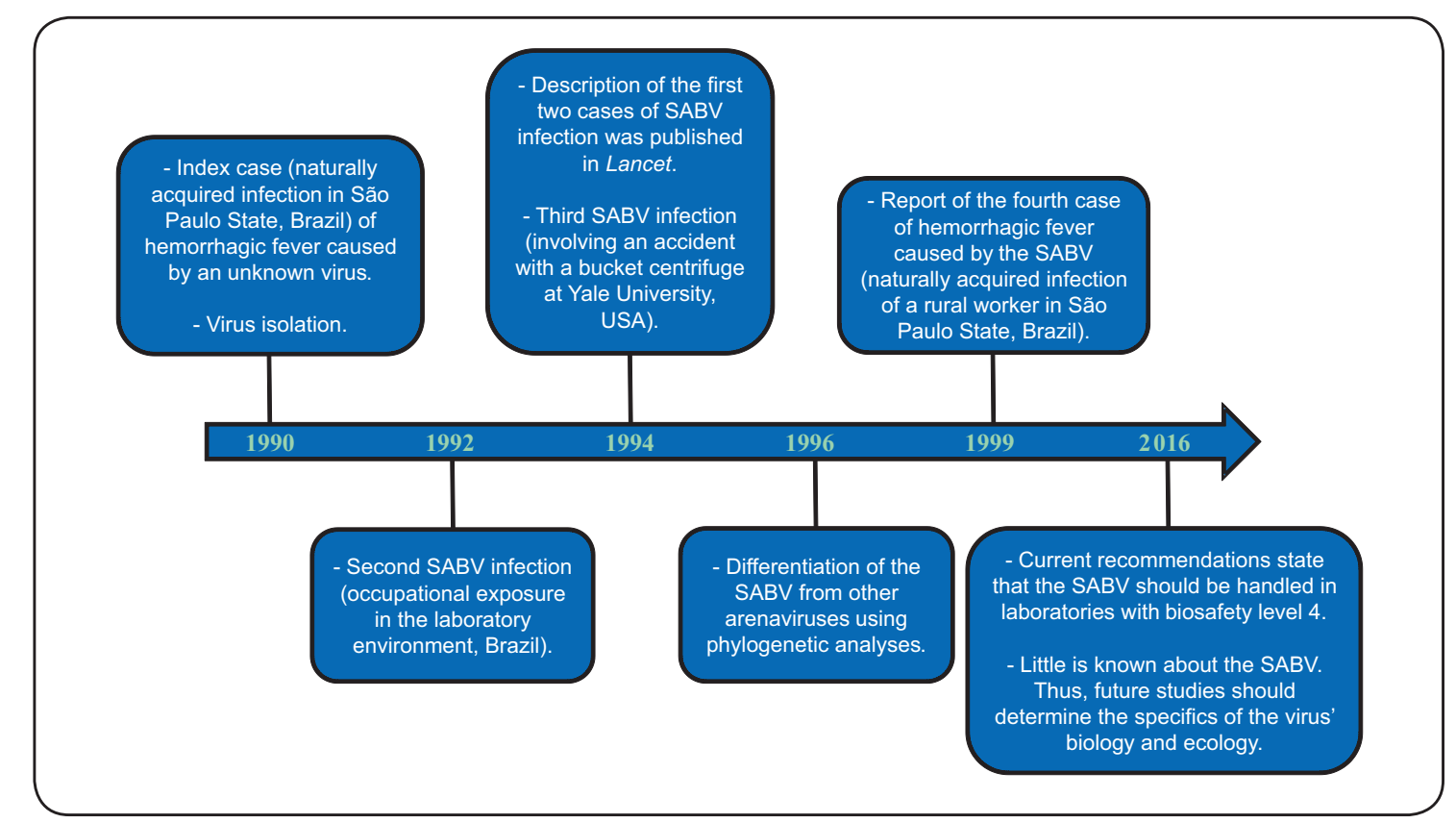

FIGURE 1 - Timeline of the main events related to the history of the Sabiá virus. SABV: Sabiá virus.

\section{REFERENCES}

1. Coimbra TLM, Nassar ES, Burattini MN, de Souza LTM, Ferreira IB, Rocco IM, et al. New arenavirus isolated in Brazil. Lancet. 1994;343(8894):391-2.

2. Gonzalez JP, Bowen MD, Nichol ST, Rico-Hesse R. Genetic characterization and phylogeny of Sabiá virus, an emergent pathogen in Brazil. Virology. 1996;221(2):318-24.

3. Buchmeier MJ, de la Torre JC, Peters CJ. Arenaviridae: the viruses and their replication. In: Knipe DM, Holley PM, editors. Fields virology, $5^{\text {th }}$ edition. Philadelphia: Wolter Kluwer Lippincott Williams \& Wilkins; 2007. p. 1791-1828.

4. Radoshitzky SR, Bào Y, Buchmeier MJ, Charrel RN, Clawson AN, Clegg CS, et al. Past, present, and future of arenavirus taxonomy. Arch Virol. 2015;160(7):1851-74.

5. Archer AM, Rico-Hesse R. High genetic divergence and recombination in Arenaviruses from the Americas. Virology. 2002;304(2):274-81.

6. Charrel RN, Feldmann H, Fulhorst CF, Khelifa R, de Chesse R, de Lamballerie X. Phylogeny of New World arenaviruses based on the complete coding sequences of the small genomic segment identified an evolutionary lineage produced by intrasegmental recombination. Biochem Biophys Res Commun. 2002;296(5):1118-24.

7. Charrel RN, Lemasson JJ, Garbutt M, Khelifa R, De Micco P, Feldmann $\mathrm{H}$, et al. New insights into the evolutionary relationships between arenaviruses provided by comparative analysis of small and large segment sequences. Virology. 2003;317(2):191-6.

8. Armstrong LR, Dembry LM, Rainey PM, Russi MB, Khan AS, Fischer SH, et al. Management of a Sabiá virus-infected patients in a US hospital. Infect Control Hosp Epidemiol. 1999;20(3):17682.

9. Bisordi I, Levis S, Maeda AY, Suzuki A, Nagasse-Sugahara TK, de Souza RP, et al. Pinhal virus, a New Arenavirus isolated from Calomys tener in Brazil. Vector Borne Zoonotic Dis. 2015;15(11):694-700.
10. Pfau CJ. Arenaviruses. In: Baron S, editor. Medical Microbiology. $4^{\text {th }}$ edition. Galveston (TX): University of Texas Medical Branch at Galveston; 1996. Chapter 57.

11. Koma T, Huang C, Kolokoltsova OA, Brasier AR, Paessler S. Innate immune response to arenaviral infection: a focus on the highly pathogenic New World hemorrhagic arenaviruses. J Mol Biol. 2013;425(24):4893-4903.

12. Coimbra TLM, Santos RN, Ferreira IB, Fialho DM, Mello ES, Ferreira LMHL, et al. Arenavirus: a fatal outcome. Virus Rev Res. 2001;1:14-6.

13. Radoshitzky SR, Abraham J, Spiropoulou CF, Kuhn JH, Nguyen D, $\mathrm{Li} \mathrm{W}$, et al. Transferrin receptor 1 is a cellular receptor for New World haemorrhagic fever arenaviruses. Nature. 2007;446(7131):92-6.

14. Fan L, Briese T, Lipkin WI. Z proteins of New World arenaviruses bind RIG-I and interfere with type I interferon induction. J Virol. 2010;84(4):1785-91.

15. Cardoso TAO, Navarro MBMA. Emerging and reemerging diseases in Brazil: data of a recent history of risks and uncertainties. Braz J Infect Dis. 2007;11(4):430-4.

16. Machado AM, Figueiredo GG, Campos GM, Lozano ME, Machado ARSR, Figueiredo LTM. Standardization of an ELISA test using a recombinant nucleoprotein from the Junin virus as the antigen and serological screening for arenavirus among the population of Nova Xavantina, State of Mato Grosso. Rev Soc Bras Med Trop. 2010;43(3):229-33.

17. Fajfr M, Neubauerová V, Pajer $P$, Kubíčková P, Růžek D. Detection panel for identification of twelve hemorrhagic viruses using realtime RT-PCR. Epidemiol Mikrobiol Imunol. 2014;63(3):238-44.

18. Figueiredo LTM. Febres hemorrágicas por vírus no Brasil. Rev Soc Bras Med Trop. 2006;39(2):203-10.

19. Golden JW, Maes P, Kwilas SA, Ballantyne J, Hooper JW. Glycoprotein-specific antibodies produced by DNA vaccination protect guinea pigs from lethal Argentine and Venezuelan hemorrhagic fever. J Virol. 2016;90(7):3515-29. 
20. Bolken TC, Laquerre S, Zhang Y, Bailey TR, Pevear DC, Kickner $\mathrm{SS}$, et al. Identification and characterization of potent small molecule inhibitor of hemorrhagic fever New World arenaviruses. Antiviral Res. 2006;69(2):86-97.

21. Larson RA, Dai D, Hosack VT, Tan Y, Bolken TC, Hruby DE, et al. Identification of a broad-spectrum arenavirus entry inhibitor. J Virol. 2008;82(21):10768-75.

22. York J, Dai D, Amberg SM, Nunberg JH. pH-induced activation of arenavirus membrane fusion is antagonized by small-molecule inhibitors. J Virol. 2008;82(21):10932-9.

23. Barry M, Russi M, Armstrong L, Geller D, Tesh R, Dembry L, et al. Brief report: treatment of a laboratory-acquired Sabiá virus infection. N Engl J Med. 1995;333(5):294-6.

24. Salazar M, Yun NE, Poussard AL, Smith JN, Smith JK, Kolokoltsova $\mathrm{OA}$, et al. Effect of ribavirin on Junin virus infection in guinea pigs. Zoonoses Public Health. 2012;59(4):278-85.

25. Radoshitzky SR, Kuhn JH, de Kok-Mercado F, Jahrling PB, Bavari S. Drug discovery technologies and strategies for Machupo virus and other New World arenaviruses. Expert Opin Drug Discov. 2012;7(7):613-32.
26. Tesh RB. Viral hemorrhagic fevers of South America. Biomedica. 2002;22(3):287-95.

27. Vasconcelos PFC, Travassos da Rosa APA, Rodrigues SG, Tesh R, Travassos da Rosa JFS, Travassos da Rosa ES. Infecção humana adquirida em laboratório pelo vírus SP H 114202 (Arenavirus: Família Arenaviridae): aspectos clínicos e laboratoriais. Rev Inst Med Trop São Paulo. 1993;35(6):521-25.

28. Centers for Disease Control and Prevention (CDC). Arenavirus infection - Connecticut, 1994. MMWR Morb Mortal Wkly Rep. 1994;43(34):635-6.

29. Gandsman EJ, Aaslestad HG, Ouimet TC, Rupp WD. Sabia virus incident at Yale University. Am Ind Hyg Assoc J. 1997;58(1):51-3.

30. Ryder RW, Gandsman EJ. Laboratory-acquired Sabiá virus infection. N Engl J Med. 1995;333(25):1716.

31. Chosewood LC, Wilson DE, editors. Biosafety in Microbiological and Biomedical Laboratories. $5^{\text {th }}$ edition. Atlanta, GA: Centers for Disease Control and Prevention (CDC); 2009. 438p. Available at: http://www.cdc.gov/biosafety/publications/bmbl5/BMBL.pdf

32. Ellwanger JH, Chies JAB. Emergent diseases in emergent countries: we must study viral ecology to prevent new epidemics. Braz J Infect Dis. 2016;20(4):403-4. 